\title{
A Numerical Study on the Effects of Exhaust Gas Recirculation Temperature on Controlling Combustion and Emissions of a Diesel Engine running on HCCI Combustion Mode
}

\author{
Mushtaq Ahmad Rather ${ }^{*}$ and Mohammad Marouf Wani ${ }^{1}$
}

${ }^{1}$ Department of Mechanical Engineering , National Institute of Technology, Srinagar, Kashmir, J\&K, 190006, India

\begin{abstract}
In this study a comprehensive study is carried out numerically on a single cylinder four-stroke Diesel engine operating in homogenous charge compression ignition (HCCI) mode of combustion for the effects of exhaust gas recirculation (EGR) temperature and percentage on the combustion and emission characteristics. An advanced version of ANSYS IC Engine FORTE coupled with highly efficient and detailed pre-defined industry standard chemical kinetics CHEMKIN is used to solve the chemical reaction mechanism and species thermodynamic data. The analysis was carried out at three different EGR temperatures of $363 \mathrm{~K}, 404 \mathrm{~K}$ and $513 \mathrm{~K}$ for $10 \%, 20 \%, 30 \%, 40 \%$ and $50 \%$ EGR each. The results predicted that the combustion ignition timing is advanced by increasing the EGR temperature. It was found that the combustion timing was advanced by 3 degree crank angle by increasing the temperature of EGR from 363 $\mathrm{K}$ to $404 \mathrm{~K}$ and the heat release rate was reduced by $163.85 \mathrm{~J} / \mathrm{degree}$ of crank angle. The effect of low EGR temperature is predominant at higher percentages of EGR. It was also found that the $\mathrm{CO}$ and UHC levels nearly kept constant with an increase in EGR temperature the $\mathrm{NO}_{\mathrm{x}}$ levels increase linearly with an increase in EGR temperature. The HCCI combustion in diesel engine can be controlled by adjusting the temperature and mass percentage of exhaust gas recirculation while retaining lower $\mathrm{NO}_{\mathrm{x}}$ emissions and very little increase in $\mathrm{CO}$ and unburnt hydrocarbons.
\end{abstract}

Keywords: CHEMKIN; EGR; HCCI; IC Engine FORTE; NOx; Thermal effects

\section{* Corresponding author}

Mushtaq Ahmad Rather

Mushi.3afn_15@nitsri.net

Adress: Department of Mechanical Engineering, National Institute of Technology, Srinagar, Kashmir, $\mathrm{J} \& \mathrm{~K}$, India

Tel:+919596150504

Manuscript Received 07.08.2018

Revised 13.09.2018

Accepted 14.09.2018

Doi:0.30939/ijastech..451574

\section{Introduction}

Homogenous charge compression ignition (HCCI) mode of combustion is an alternative combustion strategy for conventional diesel engine that offers the potential to high power output with significantly reduced exhaust emissions of $\mathrm{NO}_{\mathrm{x}}$ and Particulate matter $[1,2]$. HCCI engines encounter low temperatures during the combustion, producing high levels of emissions of $\mathrm{HC}$ and $\mathrm{CO}$ [3]. In HCCI engine, the fuel and air are mixed homogenously before the start of combustion. The homogenous mixture auto-ignites as a result of the temperature increase during the compression stroke and burns volumetrically in a faster process giving a parallel energy release throughout the entire combustion zone. HCCI combustion is a chemical kinetic combustion process and is influenced by various factors like incylinder pressure, temperature, fuel characteristics and composition of the charge within the cylinder. HCCI needs no centralized combustion initiation and correspondingly suffers lack of control of start of combustion [4]. Researchers have reported various strategies for the control of combustion phasing by adjusting the compressed gas temperature so that the charge mixture auto-ignites at the desired crank angle such as variable compression ratio [5], variable valve timing [6], and intake air heating [7]. The HCCI combustion and emissions are significantly affected by the initial temperature of the mixture [8]. The CO emissions can be reduced by modifying the key oxidation reaction rate constant.

Exhaust gas recirculation (EGR) is widely used to reduce the $\mathrm{NO}_{\mathrm{x}}$ emissions and is considered as the basic method to control the combustion phasing and burn rate in HCCI combustion engines. The auto-ignition and simultaneous combustion nature of HCCI engine limit the combustion 


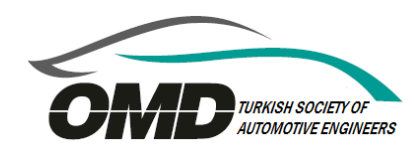

towards leaner air-fuel mixture and the exhaust gas recirculation (EGR) can be extended significantly which increases the heat capacity and lowers the heating value of the mixture resulting in lower peak pressure and temperature during the combustion, thus reducing $\mathrm{NO}_{\mathrm{x}}$ emissions [9-11]. The effect of EGR technique on combustion and emission characteristics using modified first law heat release for HCCI engine running with n-heptane/natural gas reported by Fathia et al. [12] indicated reduced mean in-cylinder temperature and rate of heat transfer as well as increased ignition delay and prolonged combustion duration. The results also revealed reduction in $\mathrm{NO}_{\mathrm{x}}$ emissions along with increase in $\mathrm{CO}$ and unburnt hydrocarbons.

Voshtani et al. [13] investigated the effects of dilution, thermodynamics and chemical kinetics on the start of combustion timing in HCCI engine fuelled with natural gas and reformed gas blend. It was found that the chemical kinetics had strong effect on the start of combustion timing than other factors. Results also showed that $\mathrm{H}_{2} \mathrm{O}$ in the combustion mixture affects significantly, while $\mathrm{CO}$ has negligible effect.

Zheng et al. [14] studied the effect of EGR on combustion characteristics of a HCCI engine fuelled with di-methyl ether using a multidimensional CFD coupled with chemical kinetic model. It was revealed that the main combustion occurred near TDC by utilizing reformed exhaust gas recirculation. The $\mathrm{NO}_{\mathrm{x}}$ emissions were reduced and there was an increase in $\mathrm{HC}$ and $\mathrm{CO}$ emissions when EGR was employed.

The EGR technique has a number of effects on the combustion process and emissions [15]. Firstly the thermal effects are related to the increase in inlet temperature of mixture which affects the volumetric efficiency and increase the specific heat of air-fuel mixture due to the presence of tri-atomic molecules of $\mathrm{CO}_{2}$ and $\mathrm{H}_{2} \mathrm{O}$. Secondly the chemical effect which is related to dissociation of species during combustion. The third effect of EGR is related dilution, which is the reduction in availability of oxygen for combustion process. Based on the literature survey the cooled EGR has a significant effect on improving the performance and emissions of a diesel engine.

This work is based on the evaluation of the important issue to investigate the effects of exhaust gas temperature on the thermal and emission characteristics of an HCCI diesel engine for different EGR rates.

\section{Computational Methodology}

\subsection{Simulation Software}

The simulation software used in this study is IC Engine FORTE 18.2 version developed by ANSYS. The software couples a highly efficient and detailed pre-defined industry standard chemical kinetics CHEMKIN which solves the chemical reaction mechanism and species thermodynamic data on the basis of Arrhenius type correlation and the CFD code is used to solve the liquid spray, turbulent gas dynamics and other transport equations.

\subsection{Computational Modeling and assumptions}

The software uses full Reynolds-averaged NavierStokes equations with the Re-Normalization Group (RNG) $\mathrm{k}-\epsilon$ model to describe the flow field. The combustion is initiated by auto-ignition in HCCI engines and the movement of charge inside the combustion chamber and the combustion chamber geometry is having very little effect on the performance of combustion [16]. In this study a single-cylinder diesel engine geometry is transformed into a sector of $60^{\circ}$ angle with periodic boundary conditions applied at the periodic faces of the sector as shown in Fig. 1 in order to reduce the computational time and improve the mesh size. The computations for were carried for the crank angle range from $570^{\circ}\left(150^{\circ}\right.$ BTDC) to $833^{\circ}\left(113^{\circ}\right.$ ATDC) comprising compression and expansion strokes. The simulation is carried for EGR temperatures of $363 \mathrm{~K}$, $404 \mathrm{~K}$ and $513 \mathrm{~K}$ for EGR mass percentages of $10 \%, 20 \%$, $30 \%, 40 \%$ and $50 \%$ each to determine the effect of the temperature of EGR along with different mass percentages on the thermal and emission characteristics of a single cylinder diesel engine running on HCCI mode.

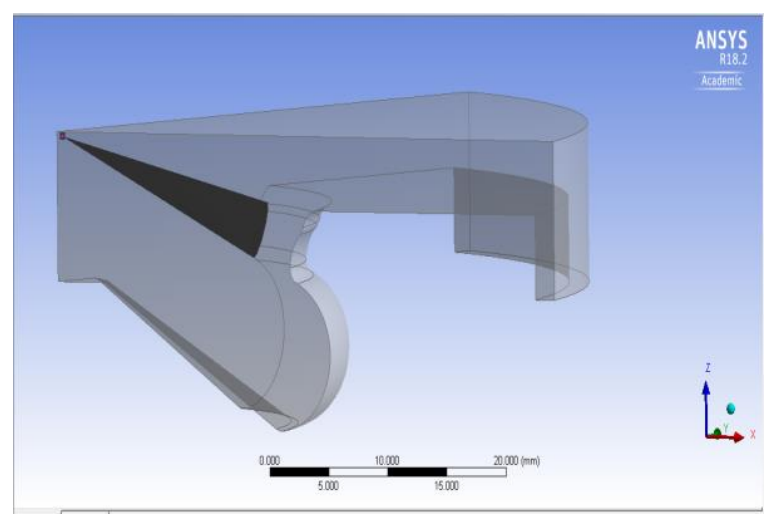

Fig. 1. A $60^{\circ}$ sector model geometry with spray cone using ANSYS Designmodeller.

A numerical grid shown in Fig. 2 containing 218364 cells was adopted to model the combustion chamber sector geometry after accomplishing the grid-independent results 


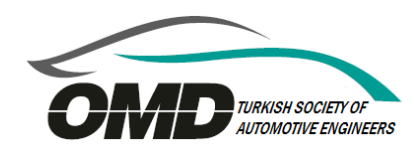

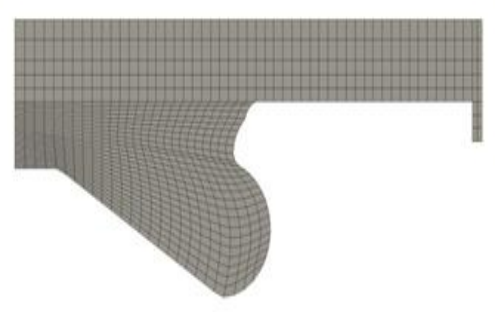

Crank Angle $=710.002$ [ degree $]$

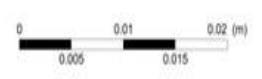

Fig. 2. A computational grid for the sector geometry using ANSYS Mesh.

The various engine geometry parameters are given in

Table 1.

Table 1. Engine Geometry Parameters

\begin{tabular}{|l|l|}
\hline Engine Parameters & \\
\hline No. of cylinders & 1 \\
\hline Bore X Stroke & $89.9 \mathrm{~mm} \mathrm{X} 110 \mathrm{~mm}$ \\
\hline Connecting rod length & $165 \mathrm{~mm}$ \\
\hline Compression ratio & 15.5 \\
\hline Engine speed & $1500 \mathrm{rpm}$ \\
\hline Squish & $4.56 \mathrm{~mm}$ \\
\hline
\end{tabular}

\subsection{Model validation}

The simulation results for the HCCI diesel engine with no EGR were compared and validated with the experimental data from for the similar engine specifications and imposing the same initial and boundary conditions.

\section{Results and discussions}

A combustion simulation has been carried out to determine the effects of exhaust gas recirculation temperature on the combustion and emission characteristics of a single cylinder four stroke diesel engine running on HCCI mode of combustion for intake exhaust gas recirculation temperatures of $363 \mathrm{~K}, 404 \mathrm{~K}$ and $513 \mathrm{~K}$ for each EGR mass per- centages of $10 \%, 20 \%, 30 \%, 40 \%$ and $50 \%$. The temperature of the entire cylinder charge depends upon the temperature and percentage of the EGR and the temperature of the air-fuel mixture. An increase in the temperature of EGR results in an increase in temperature of the entire cylinder charge. Therefore, the ignition timing of HCCI combustion can be adjusted by tuning the temperature and quantity of the EGR. Exhaust gas consists of many species, which includes the main components of burnt gases and partially burnt gases. In this study only the main components like $\mathrm{CO} 2, \mathrm{H} 2 \mathrm{O}, \mathrm{N} 2$ and $\mathrm{O} 2$ are considered. The results obtained have been discussed as under:

\subsection{Thermal effects}

Fig 3 and 4 show the effect of EGR temperature on the cylinder pressure and temperature for different EGR mass percentages respectively. A higher temperature of EGR results in the increase of thermal energy of the charge, which helps the fuel to overcome its activation energy and the pre-ignition chemical reactions are improved. The combustion ignition delay is dependent on pre-ignition chemical reactions and reduces if the engine inlet temperature is increased. It can be seen that higher the temperature of EGR, higher will be the temperature of air-fuel and EGR gas mixture, therefore the earlier ignition. The reduced ignition delay leads to an increase of peak cylinder pressure with increasing EGR mass percentage $[17,18]$. The EGR has a significant effect on cylinder temperature due to its serious effect on ignition delay. The starting time of sharp increase in cylinder pressure and temperature advances as quantity and temperature of EGR is increased. The dilution effect of EGR species results in large reductions in cylinder temperatures. 


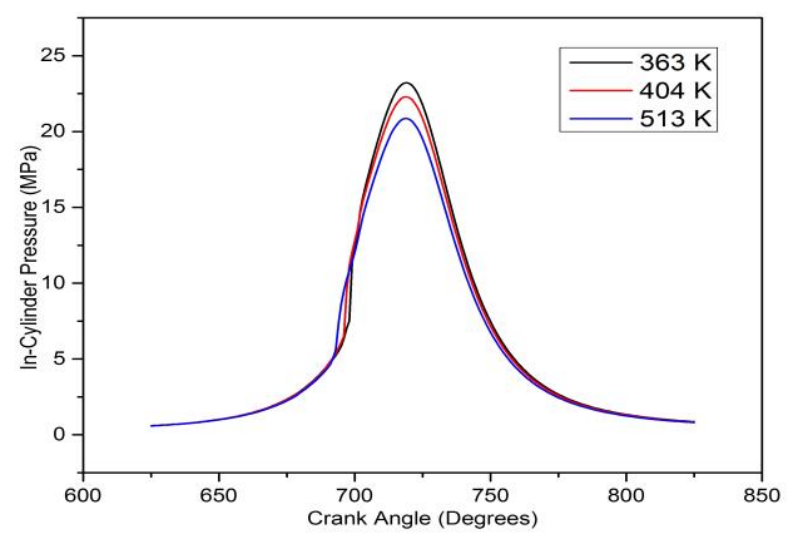

(a) $10 \%$ EGR

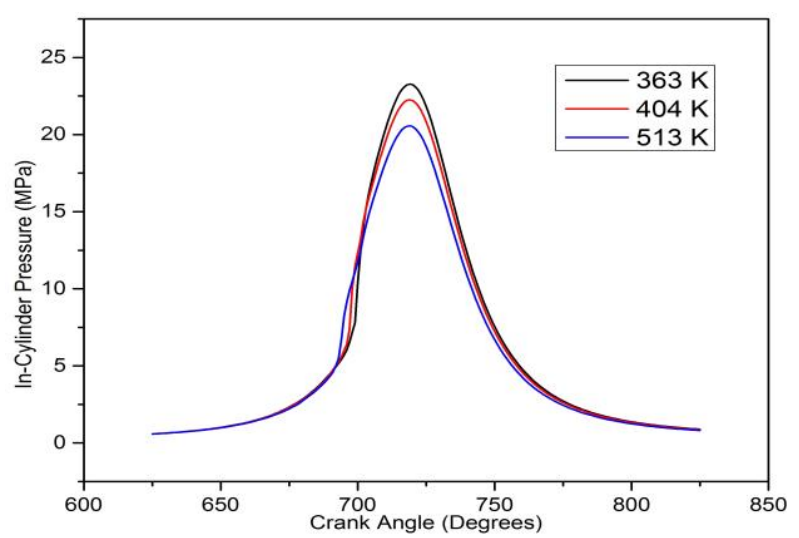

(c) $30 \% \mathrm{EGR}$

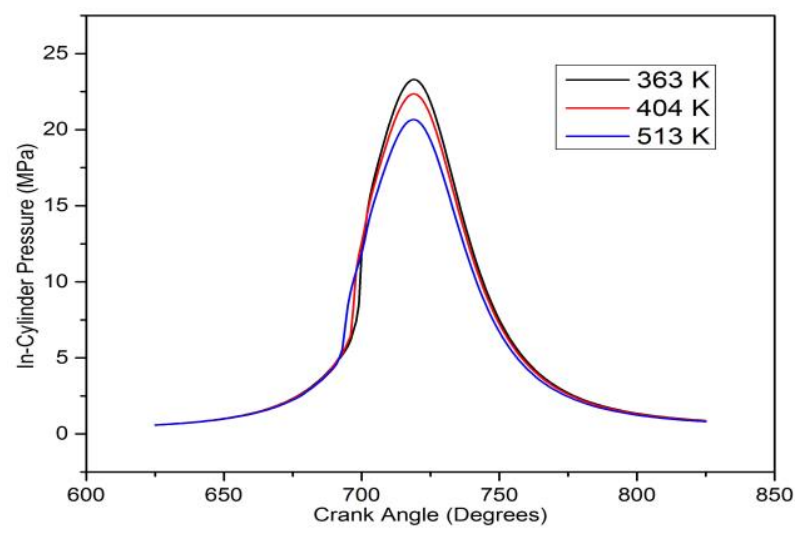

(b) $20 \%$ EGR

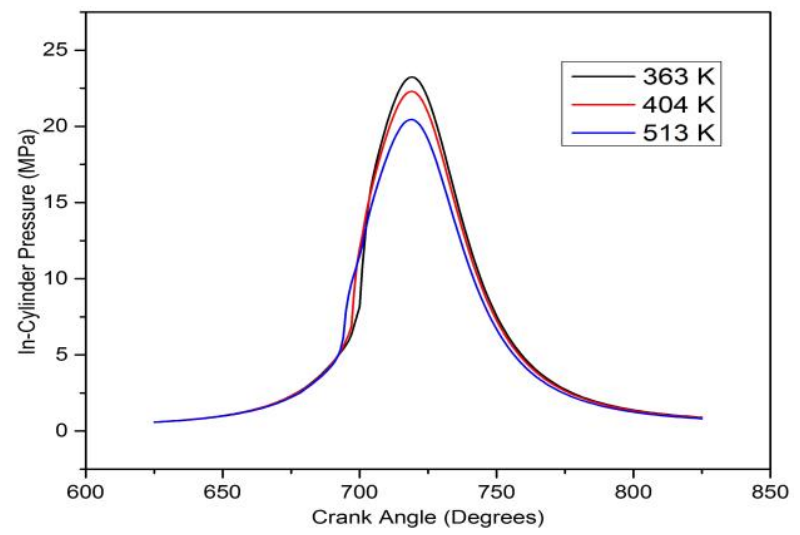

(d) $40 \%$ EGR

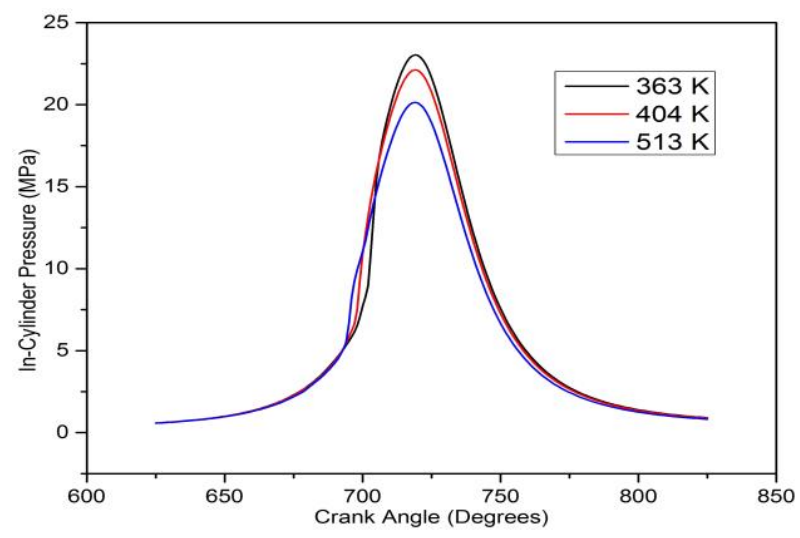

(e) $50 \%$ EGR

Fig 3. Variation of Cylinder Pressure with crank angle position for various EGR temperatures 


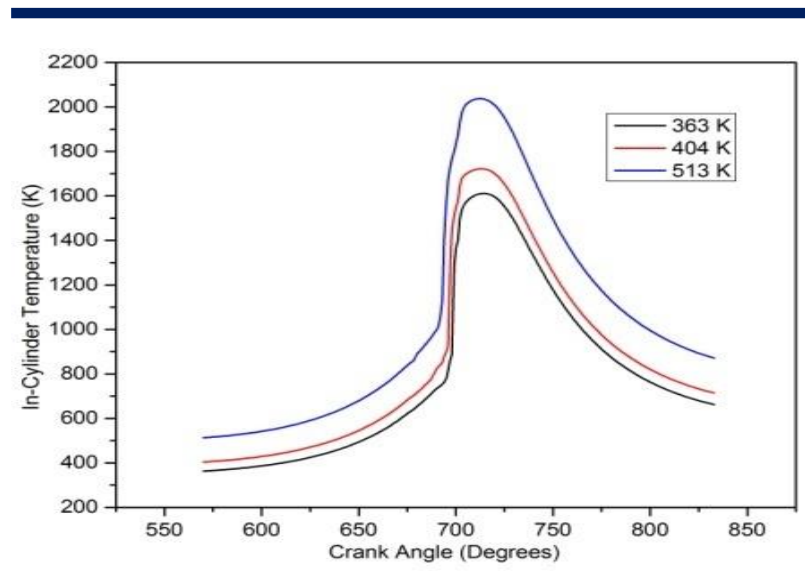

(a) $10 \%$ EGR

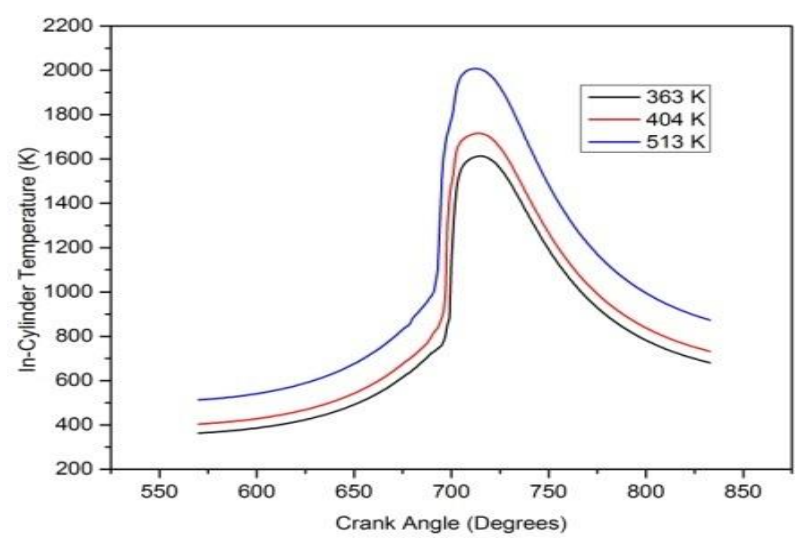

(c) $30 \% \mathrm{EGR}$

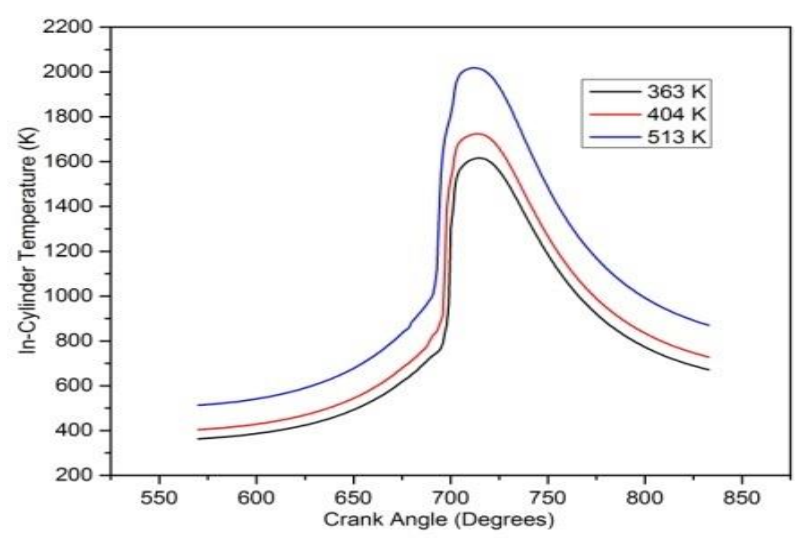

(b) $20 \%$ EGR

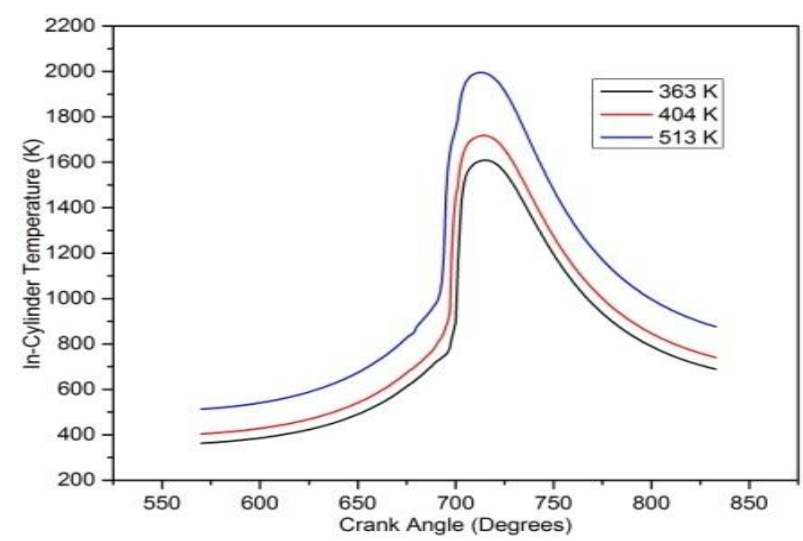

(d) $40 \%$ EGR

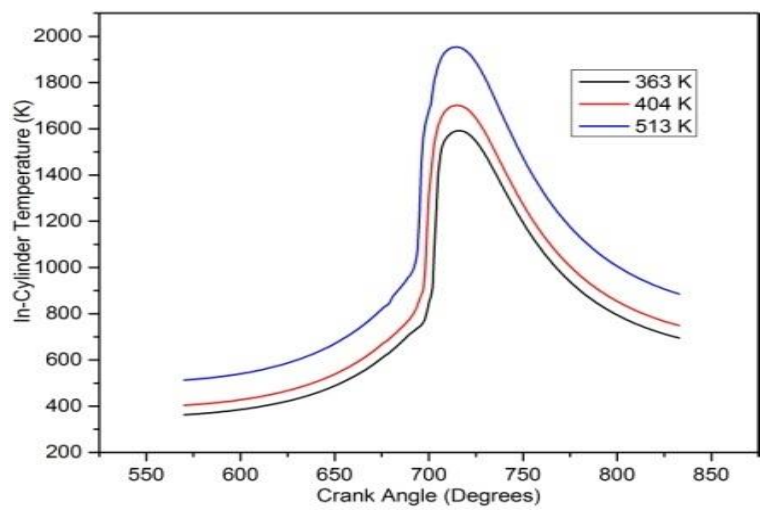

(e) $50 \%$ EGR

Fig 4. Variation of Cylinder Temperature with crank angle position for various EGR temperatures 


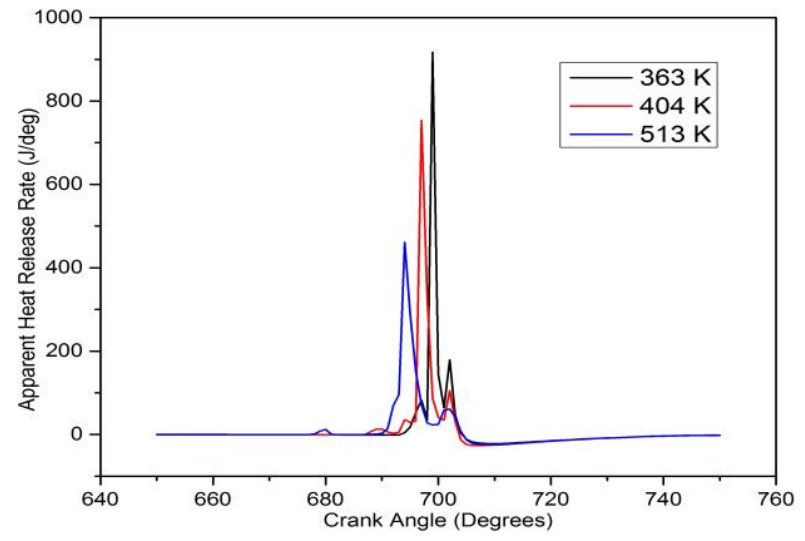

(a) $10 \%$ EGR

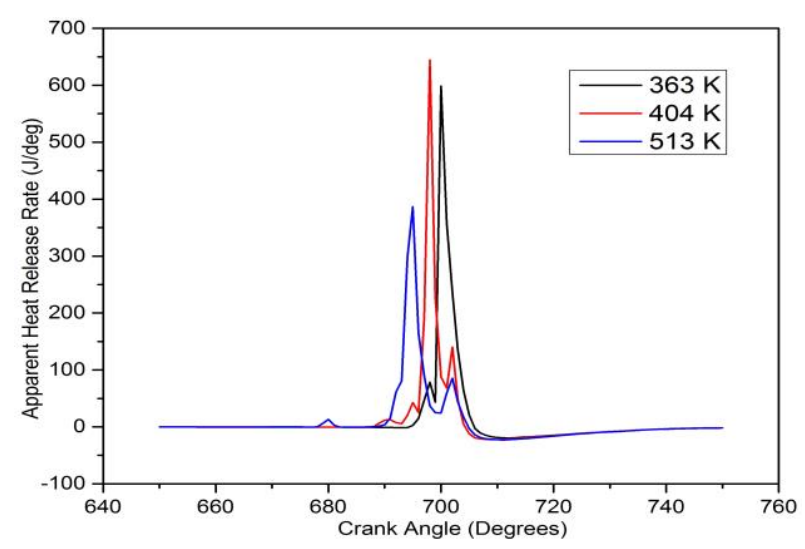

(c) $30 \% \mathrm{EGR}$

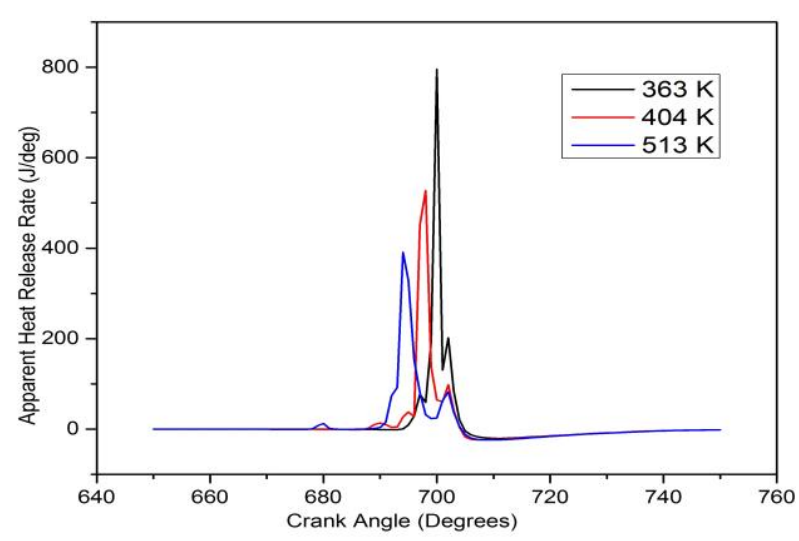

(b) $20 \%$ EGR

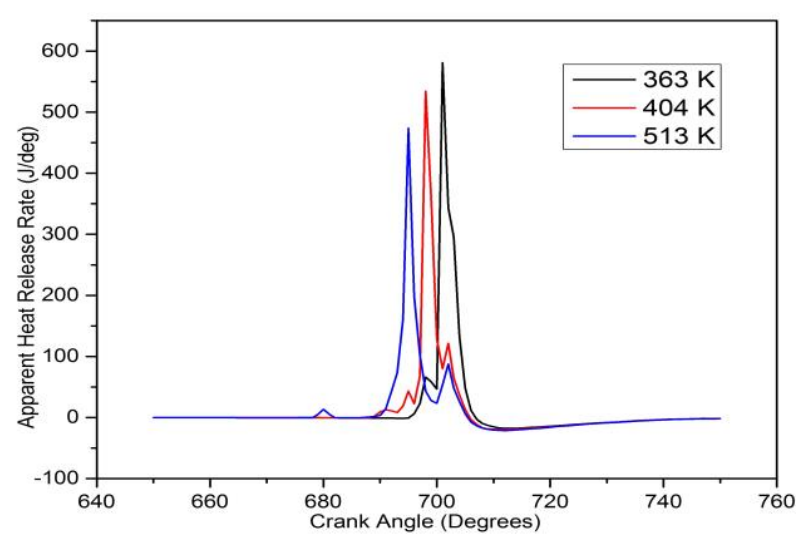

(d) $40 \%$ EGR

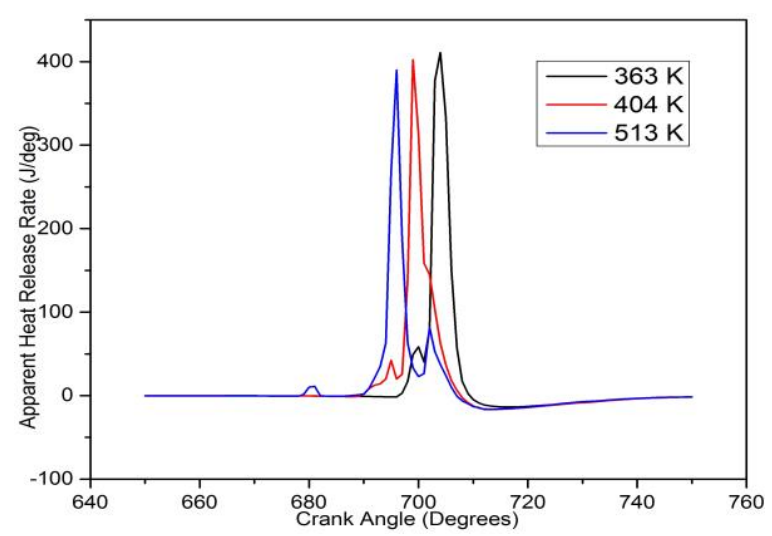

(e) $50 \%$ EGR

Fig 5. Variation of Apparent Heat Release Rate with crank angle position for various EGR temperatures

Fig 5 shows the apparent heat release rate with varying EGR temperatures for different EGR mass percentages. It can be seen that the higher temperature of EGR advances the combustion timing and the species inside the EGR dilute the combustible cylinder charge and influence both combustion ignition delays and heat release rate. With increase in EGR temperature, ignition delay is reduced and the combustion process advances and the duration of combustion increases resulting in decreased peak apparent heat release rates. 


\subsection{Emission effects}

Exhaust gas recirculation is a promised technique to reduce the $\mathrm{NO}_{\mathrm{x}}$ formation in diesel engines. Figure 6 and 7 present the variation of $\mathrm{NO}$ and $\mathrm{NO}_{2}$ formation for various EGR temperatures and EGR mass percentages.

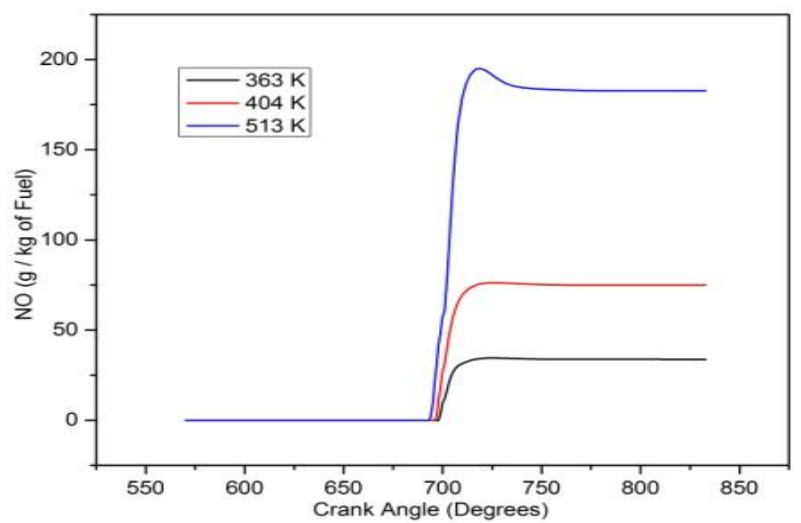

(a) $10 \%$ EGR

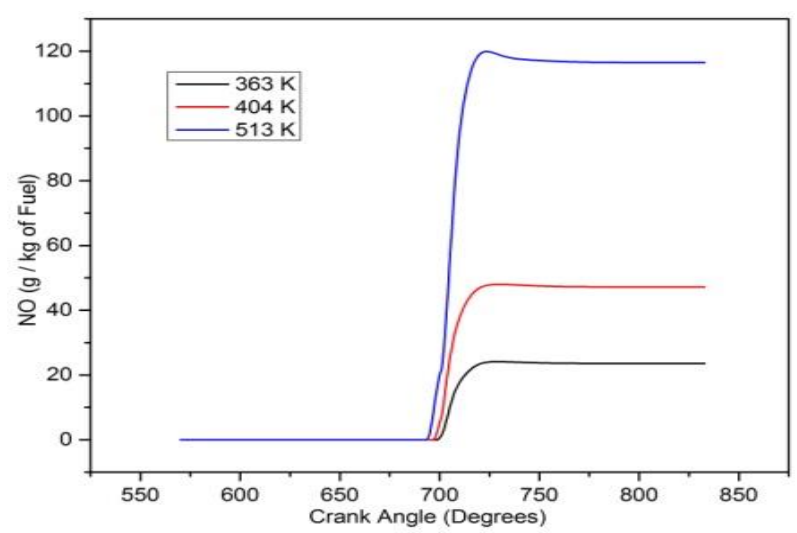

(c) $30 \%$ EGR

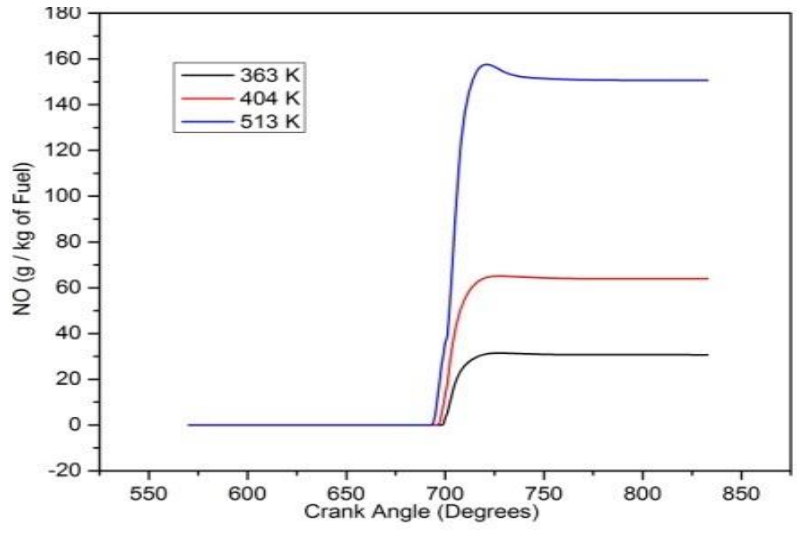

(b) $20 \%$ EGR

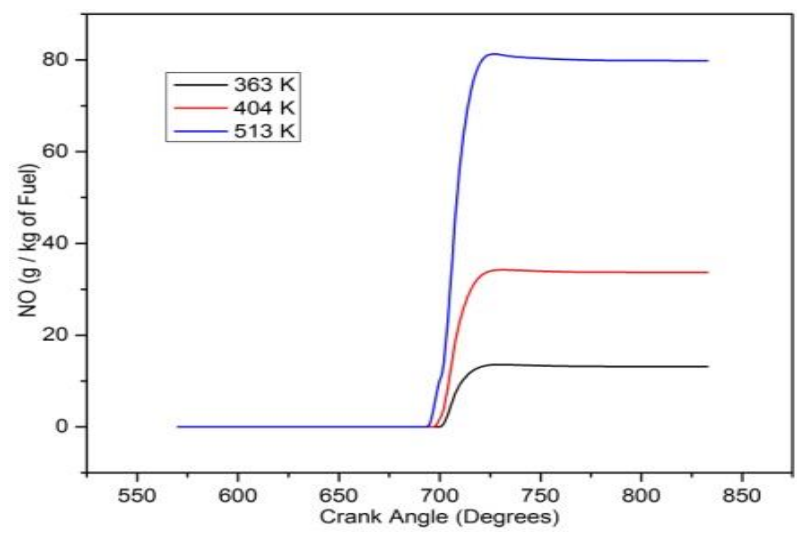

(d) $40 \%$ EGR

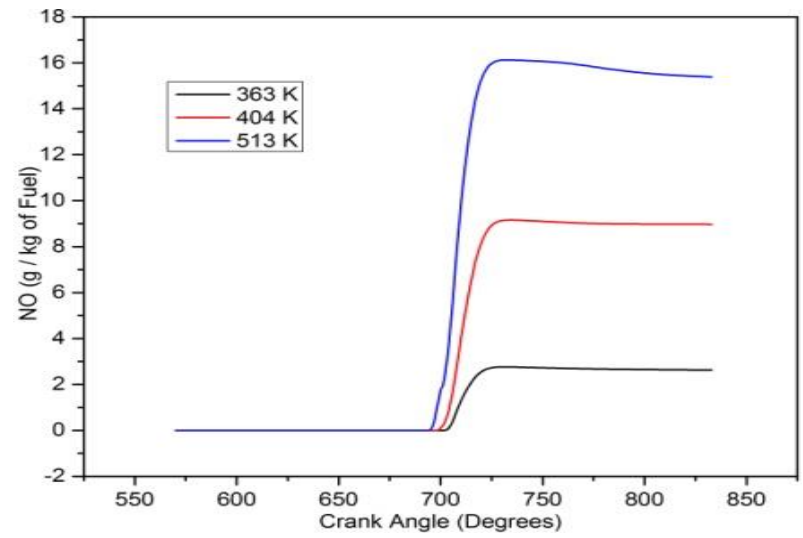

(e) $50 \%$ EGR

Fig 6. Variation of NO formation with crank angle position for various EGR temperatures 


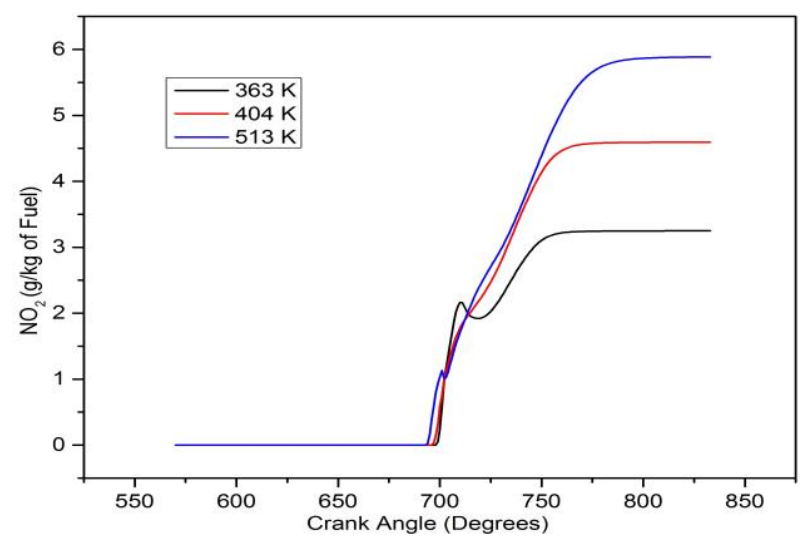

(a) $10 \%$ EGR

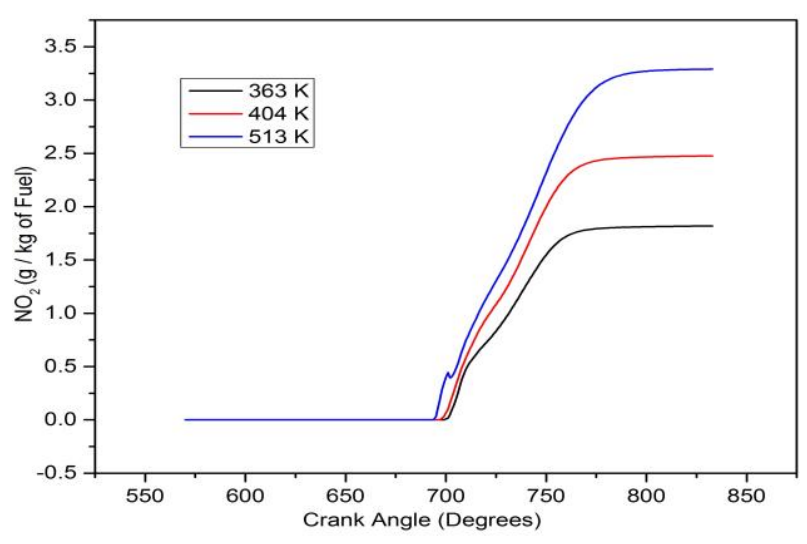

(c) $30 \%$ EGR

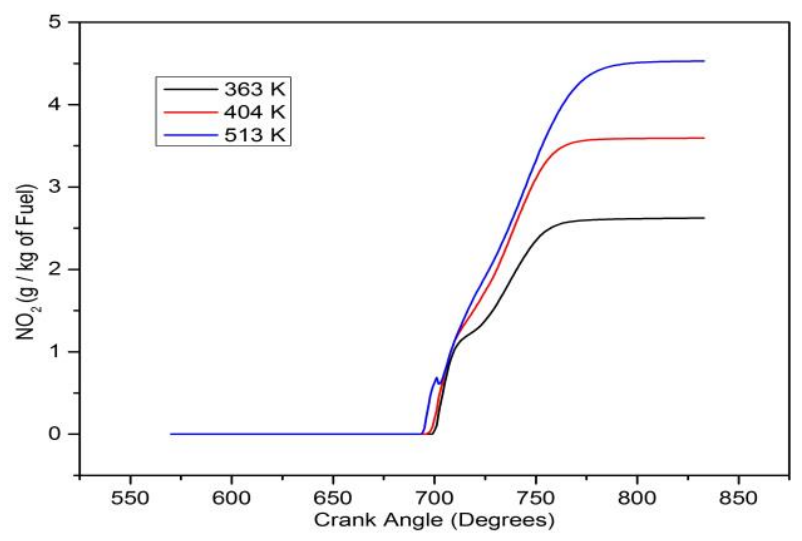

(b) $20 \%$ EGR

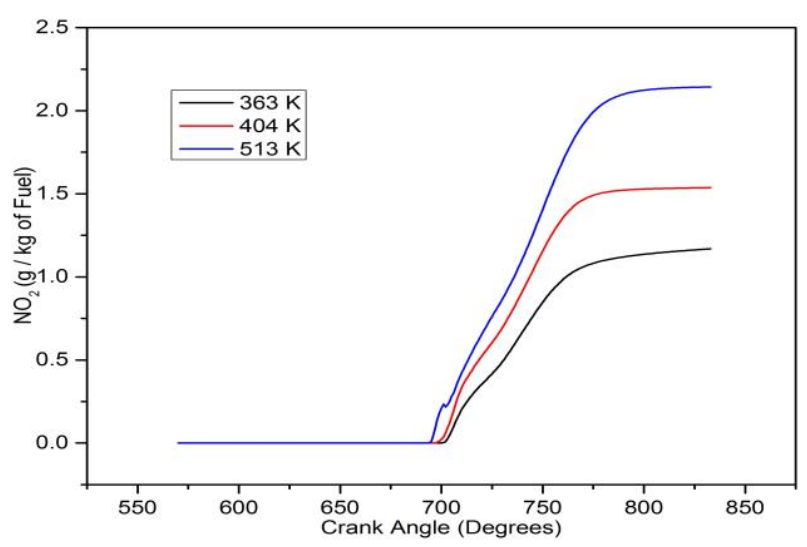

(d) $40 \%$ EGR

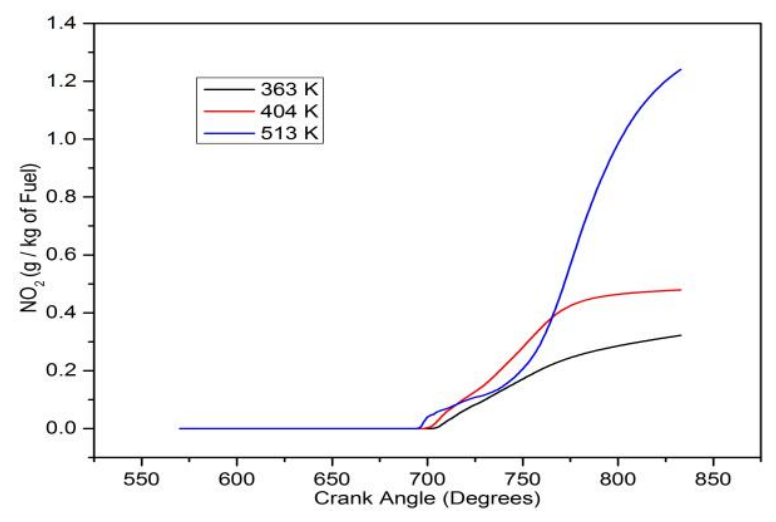

(e) $50 \%$ EGR

Fig 7. Variation of $\mathrm{NO}_{2}$ formation with crank angle position for various EGR temperatures 


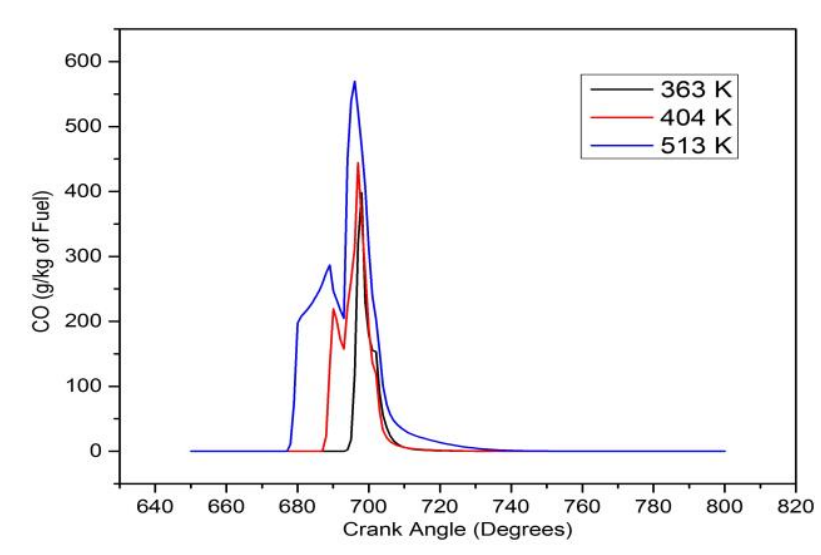

(a) $10 \%$ EGR

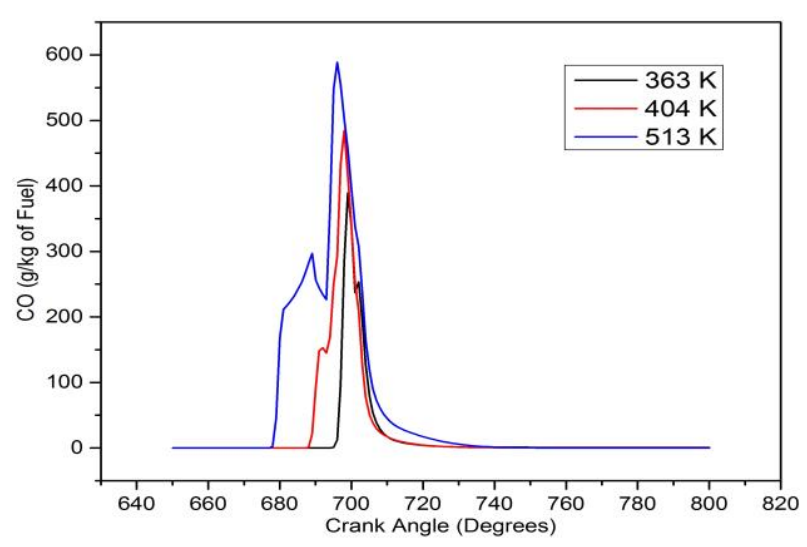

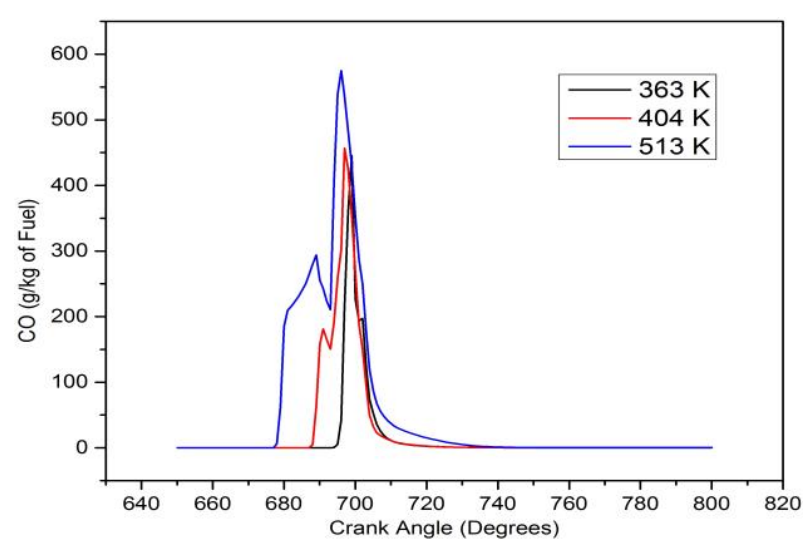

(b) $20 \%$ EGR

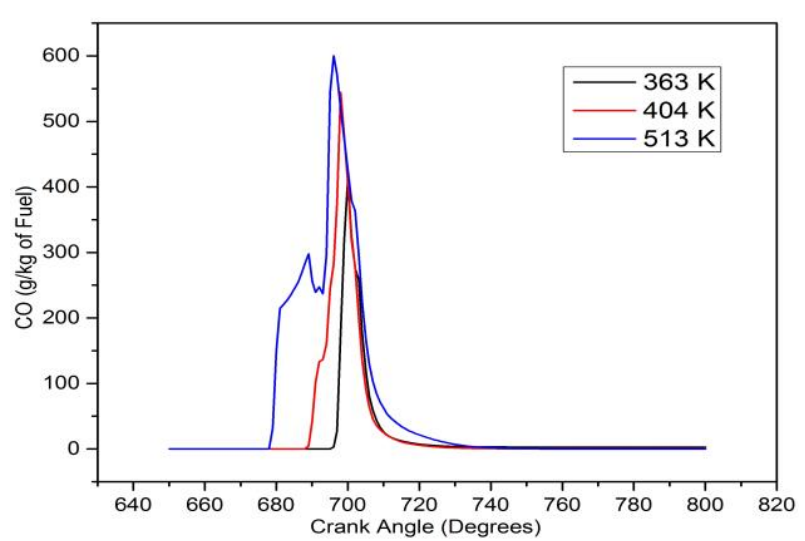

(d) $40 \%$ EGR

(c) $30 \%$ EGR

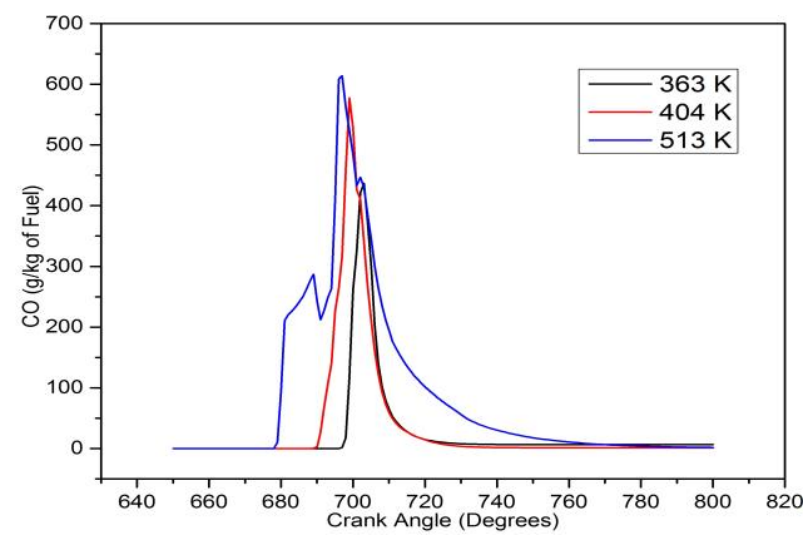

(e) $50 \%$ EGR

Fig 8. Variation of $\mathrm{CO}$ formation with crank angle position for various EGR temperatures

It is revealed from the results that the formation of $\mathrm{NO}_{\mathrm{x}}$ is dependent on the temperature and availability of oxygen within the cylinder charge. In case of high EGR temperature the charge temperatures are significantly higher and lead to an increased formation of NO. The effect of EGR temperature is more predominant at increased levels of EGR percentages.

Fig 8 and 9 present the variation of $\mathrm{CO}$ and unburnt hydrocarbons formation with crank angle position for 
various EGR temperatures. It can be seen from the results that the $\mathrm{CO}$ and $\mathrm{UHC}$ emissions slightly improve

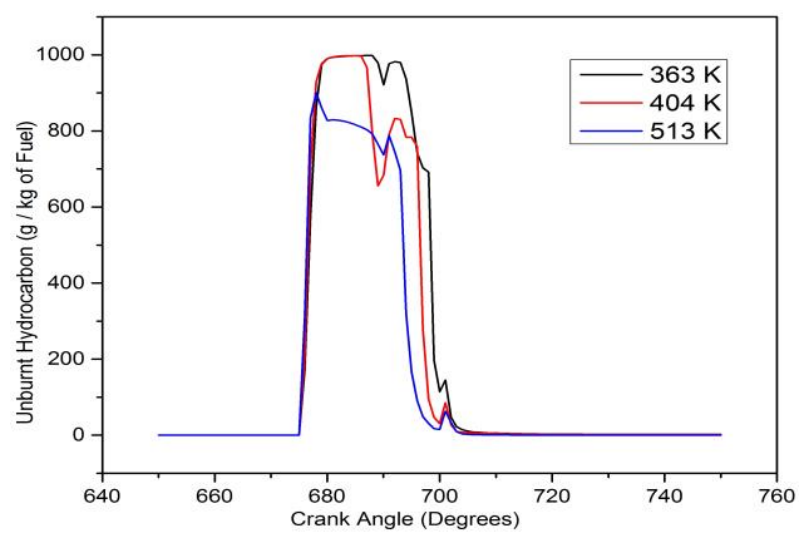

(a) $10 \%$ EGR

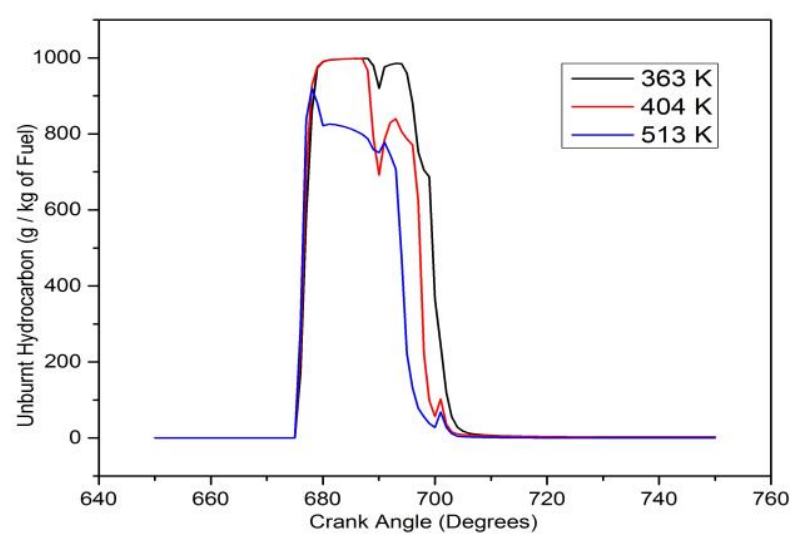

(c) $30 \%$ EGR

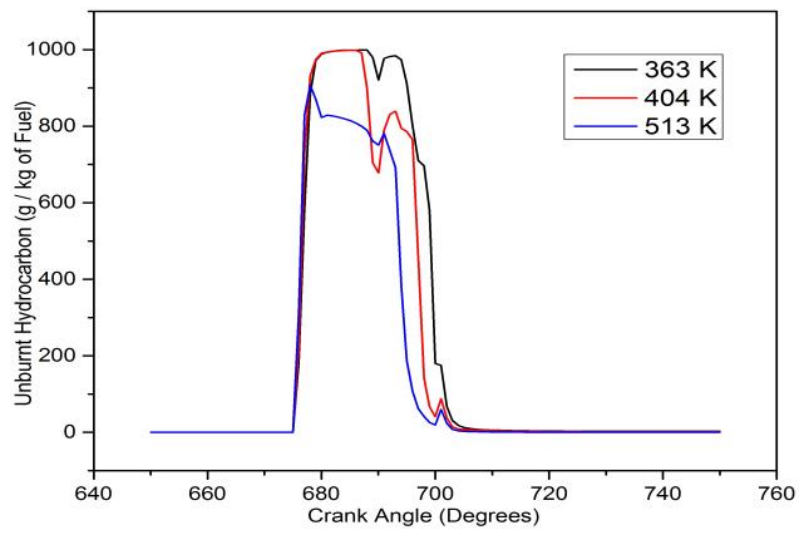

(b) $20 \%$ EGR

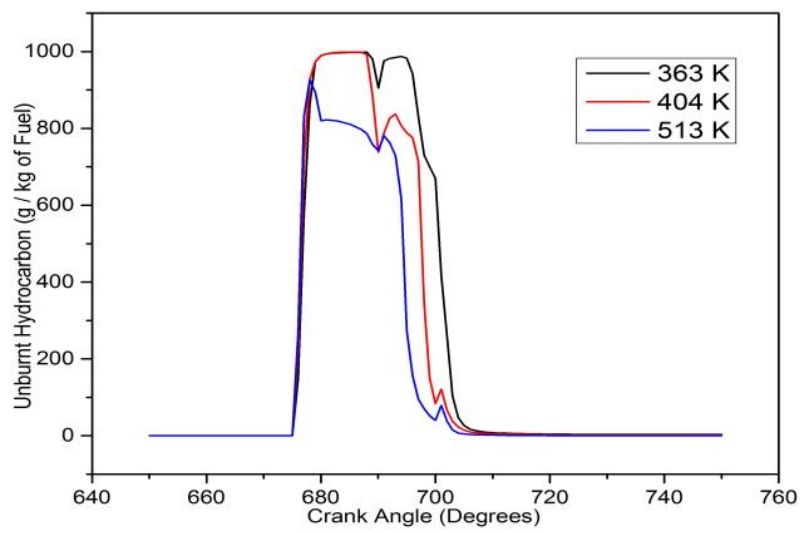

(d) $40 \%$ EGR

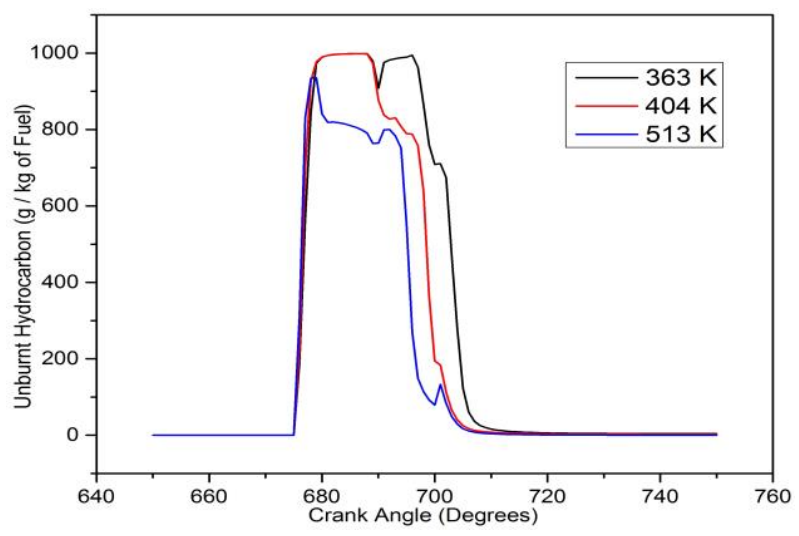

(e) $50 \%$ EGR

Fig 9. Variation of Unburnt Hydrocarbons formation with crank angle position for various EGR temperatures 


\section{Conclusions}

It can be concluded that EGR temperature has two different effects on the HCCI combustion in diesel enginesthermal and chemical effects. The thermal effects are due to the increased temperature of cylinder charge due to high temperature EGR which plays a significant role to overcome the activation energy and thereby advances the ignition timing and the various chemical species present in EGR have the dilution effects which affect both the combustion delays and apparent heat release rates. It was found that the combustion timing was advanced by 3degree crank angle by increasing the temperature of EGR from $363 \mathrm{~K}$ to $404 \mathrm{~K}$ and the heat release rate was reduced by $163.85 \mathrm{~J} /$ degree of crank angle. The effect of increased temperature of EGR at higher EGR percentages has very little effects NOx emissions. The NO2 levels increased from $1.16928 \mathrm{~g} / \mathrm{kg}$ of fuel to 1.53692 $\mathrm{g} / \mathrm{kg}$ of fuel when the temperature was increased from $363 \mathrm{~K}$ to $404 \mathrm{~K}$ and $2.14301 \mathrm{~g} / \mathrm{kg}$ of fuel at $513 \mathrm{~K}$. The reduction of oxygen concentration due to EGR and increase in EGR temperature affect both $\mathrm{CO}$ and UHC formation.

It is demonstrated in the present study that the combustion phasing can be controlled by adjusting the EGR temperature and EGR mass percentage while retaining the benefits of low $\mathrm{NO}_{\mathrm{x}}$ without significantly increasing the $\mathrm{CO}$ and UHC emissions.

\section{References}

[1] Nakamura, Y., Jung, D., Iida, N. (2013). Closed-Loop Combustion of a HCCI Engine with Re-Breathing EGR System. SAE International Journal of Engines 2013-329069.

[2] Jafarmadar, S., Nemati, P., Khodaie. R. (2015). Multidimensional modeling of the effect of exhaust gas recirculation (EGR) on exergy terms in an HCCI engine fuelled with a mixture of natural gas and diesel. Energy Conversion and Management, 105, 498-508.

[3] Mathivanan, K., Mallikarjuna, J.M., Ramesh. A. (2016). Influence of multiple fuel injection strategies on performance and combustion characteristics of a diesel fuelled HCCI engine- An experimental investigation. Experimental Thermal and Fluid Science, 77, 337-346.

[4] Yao, M., Zheng, Z., Liu. H. (2009). Progress and recent trends in homogenous charge compression ignition (HCCI) engines. Progress in Energy and Combustion Science, 35, 398-437.

[5] Haraldson, G., Tunestal, P., Johansson, B., Hyvonen, J. (2002). HCCI combustion phasing in a multicylinder engine using variable compression ratio. SAE Technical Paper, (2002-01-2858).
[6] Agrell, F., Angstrom, H.E., Erricson, B.J., Wikander, J. Linderyd, (2003). Integrated simulation and Engine test of closed loop HCCI control by aid of Variable valve timings, SAE Technical Paper, (2003-01-0748).

[7] Sjoberg, M. and Dec, J.E. (2003). Combined effects of fuel-type and engine speed on intake temperature requirements and completeness of bulk gas reactions in an HCCI engine. SAE Technical paper, (2003-01-3173).

[8] Kong, S.C., and Reitz, R.D. (2003). Numerical study of premixed HCCI engine combustion and its sensitivity to computational mesh and model uncertainties. Combust Theor Model, 2003-7-417-33.

[9] Willand, J. (1998). The Knocking syndrome-its cure and its potential. SAE Paper (982483).

[10] Christensen, M., Johansson, B. and Einewall, P. (1997). Homogenous charge compression ignition (HCCI) using isooctane, ethanol, and natural gas- A comparison with spark ignition operation. SAE Paper, (972874).

[11] Law, D., Kemp, D., Allen, J., Kirkpatrick, G., Copland, T. (2000). Controlled combustion in an IC-engine with a fully variable valve train. SAE paper (2000-01-0251).

[12] Fathia, M., Khoshbakhti, R., Saray, Checkel, M.D. (2011). The influence of exhaust gas recirculation (EGR) on combustion and emissions of n-heptane / natural gas fuelled homogenous charge compression ignition (HCCI) engines. Applied Energy, 88(12), 4719-4724.

[13] Voshtani, S., Reyhanian, M., Ehteram, M., Hosseini, V. (2014). Investigating various effects of reformer gas enrichment on a natural gas-fuelled HCCI combustion engine. International Journal of Hydrogen Energy, 39(34), 1979917809.

[14] Zheng, Z., Liu, C., Zhang, X. (2014). Numerical study of effects of reformed exhaust gas recirculation (REGR) on dimethyl ether HCCI combustion. International journal of Hydrogen Energy, 39(15), 8106-8117.

[15] Zhao, H., Peng, Z., Ladommatos, N. (2001). Understanding of controlled autoignition combustion in a four-stroke gasoline engine. Proceedings Institute of Mechanical Engineering. 215,1297-1310.

[16] Milovanovic, N., Chen, R. (2001). A review of experimental and simulation studies on controlled auto-ignition combustion. SAE Paper, (2001-01-1890).

[17] Ladommatos, N., Abdelhalim, S., Zhao, H., Hu, Z. (1998). The effects of diesel combustion and emissions of reducing inlet charge mass due to thermal throttling with hot EGR. SAE paper, (98015).

[18] Ladommatos, N., Abdelhalim, S., Zhao, H., Hu, Z. (2003). Effects of EGR on heat release in diesel combustion. SAE paper, (2003-01-0747). 